\title{
O papel do input na aquisição das vogais médias postônicas finais
}

\author{
The role of input in the acquisition of final post-tonic \\ mid-vowels
}

\author{
Susana Silva de Souza* \\ sus.work@hotmail.com \\ Secretaria da Educação do Rio Grande do Sul - IGES
}

RESUMO: O presente trabalho busca investigar o papel do input no processo variável de alçamento das vogais médias postônicas finais $-[\mathrm{e}] \sim[\mathrm{i}],[\mathrm{o}] \sim[\mathrm{u}]-$, considerando os dados longitudinais de oito crianças, com idade entre 1:3 e 2:0 (ano:meses), moradoras das cidades de Pelotas (PEL), Porto Alegre (POA) e Vista Alegre do Prata (VAP), estado do Rio Grande do Sul, e de produções de seus respectivos cuidadores. No que se refere aos dados de PEL/POA, a análise estatística evidenciou que o quadro postônico final é constituído de três vogais [a, i, u], assim como os dos seus cuidadores, os quais produziram o processo de alçamento de forma quase categórica. Quanto aos dados de VAP, os resultados revelaram a presença de duas pautas postônicas, uma, menos expressiva, constituída de três vogais [a, i, u] e outra, mais expressiva, constituída de cinco vogais [a, i, e, o, u]. Resultados semelhantes também foram encontrados nos dados dos cuidadores.

PALAVRAS-CHAVE: Aquisição da variação. Input. Vogais médias postônicas finais

\begin{abstract}
The present study investigates the role of input in final post-tonic midvowels $-[e] \sim[i],[0] \sim[u]-$ in the speech of children between the ages of 1:3 and 2:0 (year:months) and their adult caregivers living in Pelotas (PEL), Porto Alegre (POA) and Vista Alegre do Prata (VAP), in the state of Rio Grande do Sul. As to the PEL / POA data, statistical analysis showed that the final post-tonic frame is comprised of three vowels $[a, i, u]$. The caregivers showed the same results, for they produced the uprising process almost flatly. As to the VAP data, the results revealed the presence of two post-tonic sets: one is less expressive, consisting of three vowels [a, i, u], and the other, more significant, consists of five vowels [a, e, i, o, u]. Similar results were also found in the data related to the caregivers.
\end{abstract}

KEYWORDS: Variation acquisition. Input. Final post-tonic mid-vowels.

`Doutora em Linguística e Letras pela Pontifícia Universidade Católica do Rio Grande do Sul 


\section{Introdução}

Sabe-se que o alçamento das vogais médias átonas finais constitui um processo variável, bastante recorrente no Português do Sul do Brasil (VIEIRA, 1994, 2002; SILVA, 2009; MILESKI, 2013 e SOUZA, 2015) e, sabe-se, ainda, que há poucos estudos que tratam da emergência da variação na aquisição da linguagem, principalmente na região Sul do Brasil. Além disso, no que se refere aos dados longitudinais de crianças, moradoras das localidades de Pelotas, Porto Alegre e Vista Alegre do Prata, estado do Rio Grande do Sul, não há nenhum trabalho que trate sobre o tema. Por tal motivo, faz-se necessária uma investigação a fim de que se possa verificar a influência do input na aquisição das vogais postônicas finais, contribuindo, desta forma, para a descrição do português falado no Sul.

Este estudo se insere na perspectiva teórica baseada no uso (FOULKES; DOCHERTY; WATT, 2006; PIERREHUMBERT, 2003; TOMASELO, 2003; LABOV, 1972). Nesta perspectiva tenta-se explicar a variação no quadro das vogais postônicas na aquisição do Português Brasileiro (doravante PB), conciliando-a com os pressupostos metodológicos da teoria da variação (LABOV, 1972).

Com base na revisão da literatura, podemos pensar que há dois processos ocorrendo na realização das vogais postônicas finais /e/ e /o/ na fala gaúcha: a) neutralização para os dados de Pelotas/Porto Alegre (VIEIRA, 1994; 2002); e b) variação para os dados de fala dos sujeitos de Vista Alegre do Prata (MILESKI, 2013 e SOUZA, 2015). Nossa hipótese é, que por influência da localização geográfica, as vogais médias átonas se manifestam de forma diferenciada: ora como [e] e [o], ora como [i] e [u]. A imersão da criança num ambiente linguístico em que o processo de alçamento seja recorrente faz com que ela aprenda somente as vogais médias altas, por exemplo? Por que razão tal aprendiz apresentaria vogais médias átonas finais na estrutura representacional? Ou seja, o input linguístico pode estar influindo no uso de tal segmento, fazendo com que determinada vogal torne-se especializada para o contexto em questão, superando a sua concorrente.

\section{Metodologia}

Para dar conta de explicar o processo de alçamento das vogais médias postônicas finais na fala de crianças em fase inicial de aquisição da linguagem, 
propõe-se um estudo longitudinal - acompanhamento mensal por um período de seis meses (coleta realizada a cada 30 dias). Nesse sentido, tal investigação conta com dados de fala de oito crianças divididos em dois grupos por localidade, quatro sujeitos de PEL/POA (origem mista) e quatro de VAP (descendentes de italianos e poloneses), conforme procedimento adotado por Souza $(2015)^{1}$, divididos em duas faixas etárias: Faixa Etária 1 (doravante, FE1): quatro crianças com idade entre 1:3 e 1:8; e Faixa Etária 2 (doravante, FE2) ${ }^{2}$ : quatro crianças com idade entre 1:7 e 2:0 (meses: anos). A amostra para a descrição do sistema vocálico postônico final da FE1 e da FE2 é constituída de 1.565 dados.

Para checar as ocorrências das vogais nos sujeitos, foi necessário criar um arquivo com a produção de dados de cada sujeito. As produções das crianças foram transcritas foneticamente pela autora do trabalho e revisadas por linguistas da área. Fizemos uma análise minuciosa das ocorrências individuais, a fim de construir o quadro vocálico de cada informante. Na sequência, as ocorrências das vogais postônicas foram contabilizadas por faixa etária. Nessa etapa, utilizamos a planilha do Excel para o registro do número de ocorrências dos segmentos vocálicos. Por último, os dados foram rodados no programa estatístico Rbrul (JOHNSON, 2009).

\section{Descrição do Sistema postônico final}

Para tentar responder aos questionamentos formulados acima, iniciamos uma descrição detalhada das ocorrências das vogais de cada amostra (PEL/POA e VAP) de dados da fala de crianças, conforme expomos a seguir, em que foram agrupados por FE.

O Quadro 1 a seguir exibe a distribuição dos números das ocorrências dos segmentos vocálicos postônicos finais realizados pelos informantes da primeira faixa etária (FE1), a qual é constituída por quatro sujeitos (duas meninas e dois meninos), com idade entre 1:3 e 1:8. A FE2 é composta por quatro sujeitos (uma menina e três meninos), com idade entre 1:7 e 2:0.

\footnotetext{
${ }^{1}$ Com relação aos dados do estudo longitudinal, a amostra engloba crianças com idade entre 1:3 e 2:0. As entrevistas foram realizadas a cada trinta dias, por um período de seis meses. As produções das crianças foram coletadas pelo próprio cuidador (mãe/pai) por meio de interação espontânea ou estimulada (figuras, fotos, brinquedos).

${ }^{2}$ Esclarece-se que os dados dos sujeitos serão descritos conjuntamente, dentro de suas respectivas faixas etárias, a fim de se obter um número mais expressivo de ocorrências, tendo em vista a baixa produção de itens lexicais na fala das crianças nas coletas iniciais.
} 
Quadro 1: Segmentos vocálicos - [e], [o], [i], [u] - em posição postônica final contabilizados por FE

\begin{tabular}{|c|c|c|c|}
\hline Dados Contabilizados & FE1 & FE2 & Total \\
\hline VAP & 617 & 643 & 1.260 \\
\hline Pelotas & 159 & 146 & 305 \\
\hline Amostra & 776 & 789 & 1.565 \\
\hline
\end{tabular}

Fonte: Autoral

Apresenta-se a seguir, no Quadro 2, a distribuição das vogais postônicas finais realizadas pelos sujeitos da FE1 - PEL/POA. Na sequência, tem-se o Quadro 3 que corresponde ao número de ocorrências das átonas finais obtido pelos sujeitos de FE1 - VAP. Tais quadros informam os seguintes aspectos: segmento vocálico, faixa etária, número de ocorrências por etapa e total de realizações de cada segmento.

Quadro 2: Número de ocorrências contabilizadas por vogal postônica e por etapas de recolha da FE1 - PEL/POA

\begin{tabular}{|c|c|c|c|}
\hline FE1 - Idade & {$[\mathbf{i}]$} & {$[\mathbf{u}]$} & Total \\
\hline $01: 03$ & 5 & 6 & 11 \\
\hline $01: 04$ & 8 & 9 & 17 \\
\hline $01: 05$ & 8 & 7 & 15 \\
\hline $01: 06$ & 10 & 18 & 28 \\
\hline $01: 07$ & 7 & 13 & 20 \\
\hline $01: 08$ & 16 & 52 & 68 \\
\hline Total & 54 & 105 & 159 \\
\hline
\end{tabular}

Fonte: Autoral

Apresenta-se no Quadro 2 o número de ocorrências de cada segmento vocálico postônico produzido pelas crianças que integram a FE1. A vogal átona final [u] é a mais frequente, apresentando um total de 105 ocorrências, seguida da vogal [i], que apresenta 54. O Gráfico 1 a seguir evidencia que esse padrão de frequência milita em quase todas as etapas de recolha de dados. 
Gráfico 1: Valores Percentuais para [i, u], em posição postônica final, nas etapas de recolha da FE1 - PEL/POA

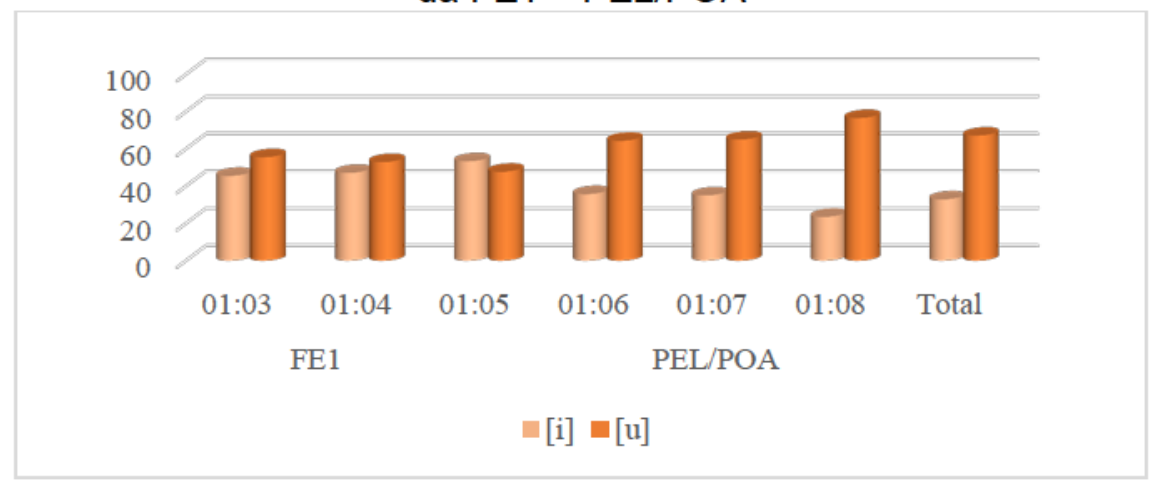

Fonte: Autoral

As formas [i] e [u] estão presentes desde a primeira faixa etária, com percentuais de 32,9 e 67,1, respectivamente. Observa-se também que o percentual de realização de [u] é mais alto a partir de 01:06. De 01:03 a 01:05, os valores para a vogal coronal [i] e para a vogal labial [u] ficam aproximados. Com base nesses resultados, é possível perceber que os dois sujeitos da localidade de PEL realizam as vogais altas em todas as suas produções de postônicas finais. Considerando que as vogais /e/, /o/, /i/ e /u/ são precocemente adquiridas, o emprego categórico das vogais altas, aqui constatado, poderia ser considerado como (i) alçamento das vogais postônicas finais /e/ e /o/ ou (ii) produção de [i] e [u] para alvos /i, u/, ou seja, a criança estaria realizando as vogais postônicas finais - $[i, \mathrm{u}]-$, simplesmente em acordo com o input do cuidador. A perspectiva emergentista acerca da aquisição da linguagem, assumida no presente artigo, leva a se considerar a hipótese (ii). No exemplo a seguir, apresentam-se as vogais postônicas finais realizadas pelos sujeitos da FE1-PEL.

(1) Vogais postônicas finais realizadas pela FE1 - PEL

$\begin{array}{ll}\text { bolo } & \text { ['bolu] (Mf -1:4) } \\ \text { vamos } & \text { ['vamu] (Mf-1:4) } \\ \text { telefone } & \text { ['foni] (Mf- 1:5) } \\ \text { peixe } & \text { ['pefi] (Am-1:6) } \\ \text { bicho } & \text { ['bifu] (Am-1:7) } \\ \text { banho } & \text { [banu] (Am-1:7) }\end{array}$

O Quadro 3 mostra as ocorrências das vogais postônicas finais produzidas pelos sujeitos da comunidade de Vista Alegre do Prata. Nota-se que os dois sujeitos 
que integram tal FE apresentam em seus sistemas postônicos quatro vogais (/e, i, o, $u /)$.

Quadro 3: Relação de produção entre médias altas e altas - Amostra crianças VAP

\begin{tabular}{|c|c|c|c|c|c|c|}
\hline$\overline{F E}$ & Idade & e/o & $\%$ & $\mathrm{i} / \mathrm{u}$ & $\%$ & Total \\
\hline \multirow[t]{2}{*}{ FE1 } & 01:03 & 12 & 66,7 & 6 & 33,3 & 18 \\
\hline & 01:04 & 54 & 85,7 & 9 & 14,3 & 63 \\
\hline \multirow[t]{4}{*}{ VAP } & $01: 05$ & 37 & 77 & 11 & 23 & 48 \\
\hline & $01: 06$ & 78 & 75 & 26 & 25 & 104 \\
\hline & 01:07 & 121 & 85,8 & 20 & 14,2 & 141 \\
\hline & 01:08 & 193 & 79,6 & 50 & 20,5 & 243 \\
\hline \multicolumn{2}{|c|}{ Total } & 495 & 80,3 & 122 & 19,7 & 617 \\
\hline
\end{tabular}

Fonte: Autoral

Considerando as relações entre médias altas e altas, verifica-se que o maior percentual de produção é para as vogais [e, o], com $80,3 \%$, contra $19,7 \%$ para [i, u]. Em relação ao percentual de realização por faixa etária, observe-se o Gráfico 2 a seguir.

Gráfico 1: Comparação entre as produções de vogais médias altas e altas - Amostra Crianças VAP

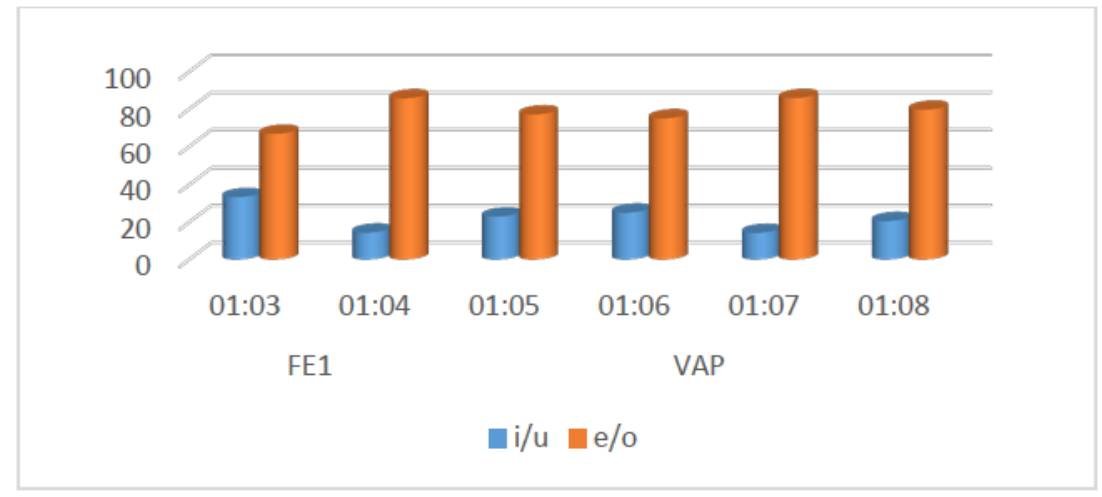

Fonte: Autoral

Pode-se comprovar, no gráfico anterior, que as crianças de VAP apresentam percentuais de realização das vogais [e, o] mais altos do que das vogais [i, u], na posição postônica final, desde as primeiras faixas etárias. O padrão variável apresentado, já nas primeiras produções, remete à composição de um sistema de cinco vogais para os aprendizes de VAP, o qual se sustenta até a última recolha de dados da FE1. Os percentuais de produção das médias altas são sensivelmente 
mais elevados nas últimas três etapas de recolha, apresentando uma possível tendência que poderá ser corroborada com a análise dos dados da FE2. No Quadro 4 , visualizam-se mais detalhes acerca das produções.

Quadro 4: Número de ocorrências contabilizadas por vogal postônica e por etapas de recolha da FE1 - VAP

\begin{tabular}{|c|c|c|c|c|c|c||c|c|c|c|c|}
\hline FE & Idade & {$[\mathrm{i}]$} & $\%$ & {$[\mathrm{e}]$} & $\%$ & Total & {$[\mathrm{u}]$} & $\%$ & {$[\mathbf{o}]$} & $\%$ & Total \\
\hline FE1 & $01: 03$ & 2 & 33,3 & 4 & 66,7 & 6 & 4 & 33,3 & 8 & 66,7 & 12 \\
\cline { 2 - 13 } & $01: 04$ & 5 & 38,46 & 8 & 61,54 & 13 & 4 & 8 & 46 & 92 & 50 \\
\cline { 2 - 13 } & $01: 05$ & 4 & 26,6 & 11 & 73,40 & 15 & 7 & 21,1 & 26 & 78,9 & 33 \\
\cline { 2 - 12 } & $01: 06$ & 10 & 45,4 & 12 & 54,60 & 22 & 16 & 19,5 & 66 & 80,5 & 82 \\
\cline { 2 - 11 } & $01: 07$ & 7 & 10,7 & 58 & 89,3 & 65 & 13 & 17,1 & 63 & 82,9 & 76 \\
\cline { 2 - 11 } & $01: 08$ & 8 & 7,5 & 98 & 92,5 & 106 & 42 & 30,6 & 95 & 69,4 & 137 \\
\hline
\end{tabular}

Fonte: Autoral

A vogal média alta [o] é a que apresenta maior número de ocorrências (304), seguida da vogal [e], que apresenta 191 ocorrências. As vogais altas [i] e [u] apresentaram números de ocorrências menores (36 e 86, respectivamente).

As quatro vogais postônicas que compõem o sistema da FE1 - VAP estiveram presentes em todas as etapas de recolha de dados. Com relação aos valores percentuais, verifica-se que as vogais altas [i] e [u] foram as que tiveram menos ocorrências em todas as faixas etárias - $15,85 \%$ e $22,05 \%$, respectivamente -, enquanto as ocorrências das vogais médias altas [e] e [o] foram mais expressivas $84,15 \%$ e $77,95 \%$. Tais realizações estão exemplificadas em (2).

(2) Vogais postônicas finais realizadas pela FE1 - VAP

abre ['abi] (Ff-1:4)

livro ['ivo] (Ff-1:5)

vamos ['vamu] $(\mathrm{Pm}-1: 5)$

esse ['ese] (Ff-1:6)

dedo ['dedo] $(\mathrm{Pm}-1: 6)$

Nos Quadros 5 e 6, apresentam-se os valores globais referentes aos sujeitos que constituem a FE2. Tais quadros estão organizados da seguinte forma: o Quadro 5 é constituído por dados de apenas um informante que pertence à comunidade de 
Pelotas ${ }^{3}$. O Quadro 6 é composto por três informantes pertencentes à comunidade de Vista Alegre do Prata. Essa faixa etária apresenta um total de 789 produções.

Quadro 5: Número de ocorrências contabilizadas por vogal postônica e por etapas de recolha da FE2 - PEL

\begin{tabular}{|c|c|c|c|c|}
\hline FE & Idade & [i] & {$\left[u^{\prime}\right]$} & Total \\
\hline \multirow{2}{*}{ FE2 } & 01:07 & 4 & 4 & 8 \\
\hline & $01: 08$ & 12 & 8 & 20 \\
\hline \multirow{4}{*}{ PEL } & 01:09 & 4 & 8 & 12 \\
\hline & $01: 10$ & 8 & $\overline{12}$ & 20 \\
\hline & $01: 11$ & 23 & 35 & 58 \\
\hline & $02: 00$ & 6 & 22 & 28 \\
\hline \multicolumn{2}{|c|}{ Total } & 57 & 89 & 146 \\
\hline
\end{tabular}

Fonte: Autoral

Esclarece-se que FE2 é composta de apenas um informante menino. Assim, os números de dados expostos no Quadro 5 refere-se ao sujeito Mn.

O quadro anterior mostra o sistema postônico final do sujeito que integra a FE2 da comunidade de PEL. Verifica-se que as vogais [e] e [o] foram realizadas, assim como na FE1, categoricamente como [i] e [u]. Das 146 ocorrências, 89 foram para a vogal [u] e 57 para a vogal [i], ou seja, mais uma vez, o alvo labial é mais frequente do que o coronal.

Diante do apresentado, pode-se dizer que os resultados tanto para a FE1 quanto para a FE2 são semelhantes, confirmando, portanto, que, nas localidades de PEL e POA, as realizações de [i, u] são categóricas, com uma maior frequência da vogal labial ao longo do desenvolvimento da aquisição. As ocorrências com realizações categóricas dos segmentos vocálicos postônicos finais [i] e [u] pela FE2 PEL são apresentadas nos exemplos a seguir.

(3) Vogais postônicas finais realizadas pela FE2 - PEL

$$
\begin{aligned}
& \text { leite ['letfi] }(\mathrm{Mn}-1: 7 \mathrm{Mn}) \\
& \text { sabi ['sabi] }(\mathrm{Mn}-1: 8) \\
& \text { dedo ['dedu] }(\mathrm{Mn}-1: 8) \\
& \text { xavante [sa'vãtsi ] }(\mathrm{Mn}-1: 11) \\
& \text { palhaço [pa'lasu] (Mn-1:11) }
\end{aligned}
$$

${ }_{3} \overline{\mathrm{Na} F E 2}$ de PEL/POA, apenas um informante participou da coleta. 
O Quadro 6 a seguir apresenta o número de ocorrências das vogais postônicas finais dos sujeitos de VAP. A comparação entre os resultados das vogais médias altas e os das altas indica que há uma diferença considerável entre os dois grupos de vogais.

Quadro 6: Relação entre índices das vogais postônicas finais da FE2 - VAP

\begin{tabular}{|c|c|c|c|c|c|}
\hline Idade & $\mathbf{i} / \mathbf{u}$ & $\mathbf{\%}$ & $\mathbf{e} / \mathbf{0}$ & $\mathbf{\%}$ & Total \\
\hline $01: 07$ & 8 & 25 & 24 & 75 & 32 \\
\hline $01: 08$ & 10 & 22,7 & 34 & 77,3 & 44 \\
\hline $01: 09$ & 19 & 15,3 & 105 & 84,7 & 124 \\
\hline $01: 10$ & 27 & 19,8 & 109 & 80,2 & 136 \\
\hline $01: 11$ & 38 & 25,6 & 110 & 74,4 & 148 \\
\hline $02: 00$ & 33 & 20,7 & 126 & 79,3 & 159 \\
\hline Total & $\mathbf{1 3 5}$ & $\mathbf{2 0 , 9}$ & $\mathbf{5 0 8}$ & $\mathbf{7 9 , 1}$ & $\mathbf{6 4 3}$ \\
\hline
\end{tabular}

Fonte: Autoral

$\mathrm{Na}$ FE2, as vogais médias átonas finais apresentam variação: ora são realizadas como [e, o], ora são realizadas como [i, u]. No Quadro 7, mais detalhes podem ser observados. A vogal átona [o] é a mais frequente, apresentando 324 ocorrências, seguida da vogal [e], com 184 produções. Nota-se também a presença das vogais altas [i] com apenas 17 ocorrências e a vogal átona [u], com 118 realizações.

Quadro 7: Número de ocorrências contabilizadas por vogal postônica e por etapas de recolha da FE2 - VAP

\begin{tabular}{|c|c|c|c|c|c|c|c|c|c|c|c|}
\hline FE & Idade & {$[\mathbf{i}]$} & $\%$ & {$[\mathrm{e}]$} & $\%$ & Total & {$[\mathrm{u}]$} & $\%$ & {$[\mathbf{0}]$} & $\%$ & Total \\
\hline FE2 & $01: 07$ & 2 & 20 & 8 & 80 & 10 & 6 & 27,2 & 16 & 72,8 & 22 \\
\cline { 2 - 12 } & $01: 08$ & 2 & 40 & 3 & 60 & 5 & 8 & 20,5 & 31 & 79,5 & 39 \\
\cline { 2 - 12 } & $01: 09$ & 2 & 5 & 40 & 95 & 42 & 17 & 20,7 & 65 & 79,3 & 82 \\
\cline { 2 - 11 } & $01: 10$ & 4 & 10 & 36 & 90 & 40 & 23 & 23,9 & 73 & 76,1 & 96 \\
\cline { 2 - 11 } & $01: 11$ & 3 & 6,6 & 43 & 93,4 & 46 & 35 & 34,3 & 67 & 65,7 & 102 \\
\cline { 2 - 10 } & $02: 00$ & 4 & 6,9 & 54 & 93,1 & 58 & 29 & 28,7 & 72 & 71,3 & 101 \\
\hline \multicolumn{2}{|c|}{ Total } & 17 & 8,45 & 184 & 91,55 & 201 & 118 & 26,69 & 324 & 73,31 & 442 \\
\hline
\end{tabular}

Fonte: Autoral

Os valores que constam nesse quadro mostram que as vogais átonas finais [e] e [o] - 91,55\% e 73,31\% - apresentam ocorrências bem mais expressivas do que as formas [i] e [u] $-8,45 \%$ e $26,69 \%$. Esses resultados confirmam que, no sistema 
postônico das crianças de VAP, há a presença de cinco vogais, já sinalizada com base nos resultados da FE1. Em (4), alguns exemplos de produções realizadas pelas crianças da FE2 - VAP.

(4) Vogais postônicas finais realizadas pela FE2 - VAP

$\begin{array}{ll}\text { olho } & \text { ['ojo] ( Am- 1:7) } \\ \text { bala } & \text { ['bala] (Ff- 1:8) } \\ \text { Eduardo } & \text { ['ado] (Nm- 1:8) } \\ \text { abre } & \text { [abi] (Ff- 1:7) } \\ \text { esse } & \text { ['ese] (Mm-1:9) } \\ \text { esse } & \text { ['eSi] (Mm- 1:7) } \\ \text { bolo } & \text { ['bolu] (AM- 1:9) }\end{array}$

Observa-se que, nos exemplos aqui reportados, constatam-se formas variáveis até mesmo nas produções de um mesmo informante, ainda que em datas de recolha de dados distintas, a saber esse, produzido por Mm como ['eSi], aos 1:7, e como ['ese], aos 1:9.

Assim como foi constatado para as produções da FE1 - VAP, o transcorrer da recolha de dados evidencia maior realização de [e] em detrimento de [i], com o avançar da idade - aos 1:8, [i] atinge $40 \%$ de realização, aos 2:0, 6,9\%. Desta forma, a partir de 1:7, os dados parecem evidenciar uma mudança em relação à produção da coronal final, com maior predominância do que talvez, aqui, já se possa chamar de aplicação do processo de alçamento.

Com base nas descrições das postônicas finais aqui realizadas, postula-se que o quadro vocálico postônico final das crianças de PEL/POA deste estudo é composto por três vogais; já as crianças de VAP apresentam cinco. Dessa forma, é possível perceber que a localização geográfica exerce um papel fundamental na constituição do sistema vocálico postônico das crianças gaúchas. Esses resultados corroboram os já postulados por Vieira $(1994,2002)$ e Mileski $(2013)$, referentes aos dados de adultos. Confirma-se também a aquisição precoce dos segmentos vocálicos pela criança, conforme Rangel (2002), também em posição postônica final.

Embora haja indícios de um processo variável na fala das crianças de VAP já desde as coletas iniciais, ou seja, a partir de 1:3, é possível considerar a hipótese de que, até 1:6, quando o percentual de aplicação do processo de alçamento atinge índices menos elevados, as produções - ora de [e, o], ora de [i, u] finais - refletem apenas o papel do input na aquisição. Assim, nas primeiras coletas, haveria uma 
maior assonância entre as produções realizadas pela criança - se com a vogal média alta ou com a vogal alta - e as produções realizadas pelo seu cuidador. $O$ aumento gradual da aplicação do alçamento, constatado no transcorrer da aquisição, até o momento, para a vogal coronal, refletiria, então, a militância do processo variável.

De acordo com Pierrehumbert $(2001,2003)$, o falante/ouvinte armazena em sua memória todas as informações relacionadas às suas experiências com a língua. Tais informações estão organizadas em um mapa cognitivo e são afetadas pela frequência ou pela repetição com que a criança é exposta à determinada forma linguística. No caso do alçamento das vogais médias átonas finais, sugere-se que as crianças estão construindo tal processo por meio de suas experiências com o uso da língua.

\section{A Relevância do input na aquisição do sistema postônico final}

No processo de aquisição da linguagem, muito se tem discutido sobre o papel do input na construção linguística da criança. Para muitos autores (PIERREHUMBERT, 2001; TOMASELO, 2000) o input linguístico se refere ao conjunto de experiências proporcionadas pelo uso real da língua humana nas suas diversas interações comunicativas, como os gestos e a fala.

Tomasello (2003) e Pierrehumbert $(2001,2003)$ postulam que a aquisição da linguagem não depende apenas de capacidades cognitivas, conforme defendida por Chomsky (1965, 1981), mas de uma complexa interação entre o desenvolvimento sociocognitivo e o input linguístico. De acordo com os autores, é o input que faz a diferença no aprendizado da criança, ou seja, quanto mais input a criança recebe, mais forte vai ficando sua experiência com a língua. Dessa forma, pode-se sugerir que a emergência gramatical é determinada pelo input, enquanto as produções mais precoces poderiam evidenciar a militância de aspectos outros, como os de maturação perceptual e articulatória, no que concerne à aquisição fonético/fonológica, por exemplo.

Tendo em vista que as crianças deste estudo apresentaram resultados diferenciados para aquisição do sistema postônico final - tanto em relação às duas localidades como em relação às idades dos aprendizes -, postula-se que essa aquisição seja efetivamente influenciada pelo input. Assim, a fim de confirmar essa 
relação, apresentam-se a seguir os dados dos cuidadores das crianças de VAP das faixas etárias 1 e 2 .

Com relação aos cuidadores da FE1, observa-se no Gráfico 7 a seguir que as vogais médias altas átonas finais [e] e [o] são as que apresentam índices de produção mais altos, com $98,8 \%$ e $87,1 \%$, respectivamente. Já as vogais [i] e [u] exibem índices mais baixos, com $1,2 \%$ e $12,9 \%$, respectivamente.

Gráfico 3: Percentual de ocorrências das vogais postônicas finais na FE1 Amostra Cuidadores VAP

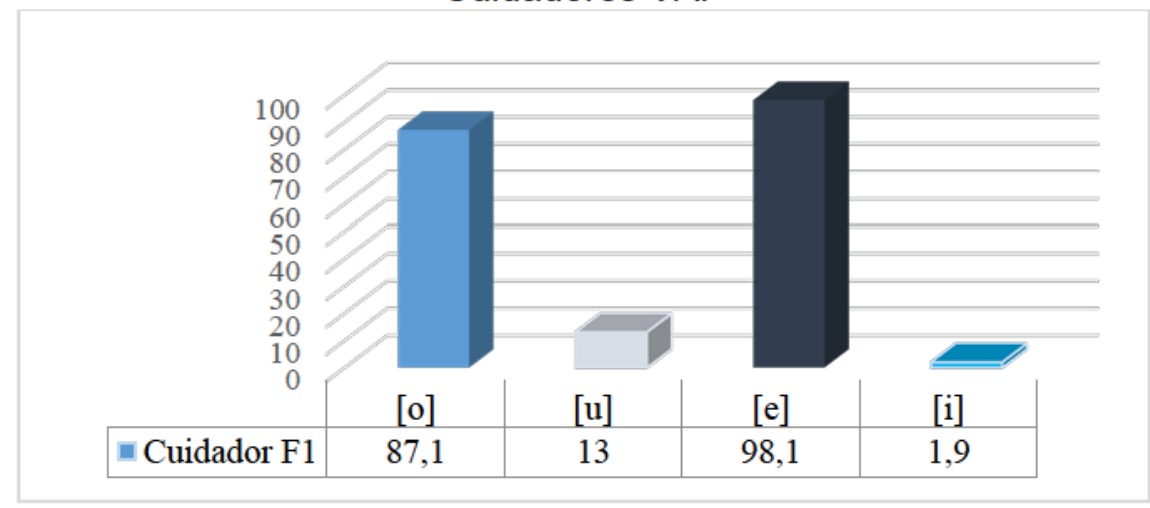

Fonte: Autoral

Nota-se que tanto EF quanto PM apresentam mais ocorrências das vogais [e, o] em suas produções do que das vogais [i, u]. De acordo com os resultados obtidos nas produções dos cuidadores da FE1, verifica-se a clara predominância da produção das vogais médias altas em posição postônica final - [e, o], com 91,4\% e [i, u], com $8,6 \%$. O Gráfico 8 a seguir exibe as diferenças dos valores das médias altas e das vogais altas.

Gráfico 4: Percentual de ocorrências das vogais postônicas finais - Cuidadores FE1-VAP

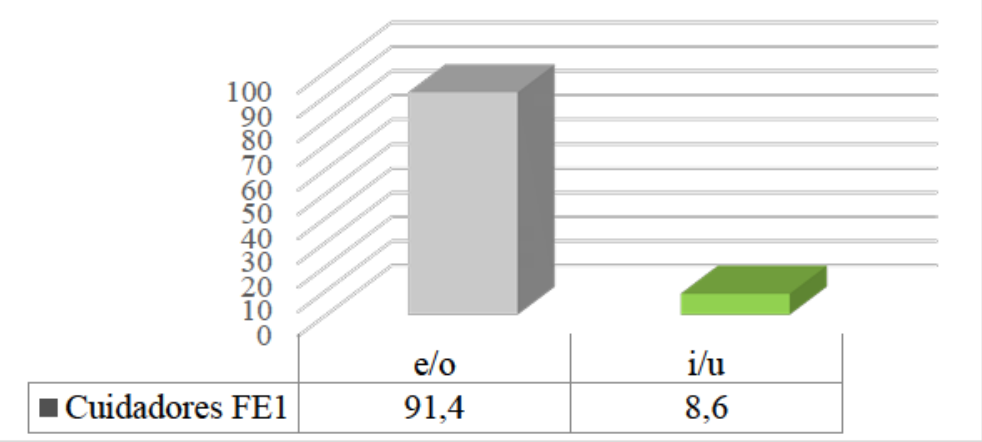

Fonte: Autoral 
Levando-se em conta os resultados obtidos nos dados das crianças da FE1 VAP e de seus cuidadores, em relação às produções das vogais médias altas e altas, observa-se que há muitas semelhanças entre os resultados. Assim como os adultos, as crianças também apresentaram índices elevados a favor das vogais médias altas. Essa comparação entre resultados está expressa no Gráfico 9.

Gráfico 5: Percentuais de ocorrências das vogais médias altas e altas na FE1-VAP, cuidadores e crianças

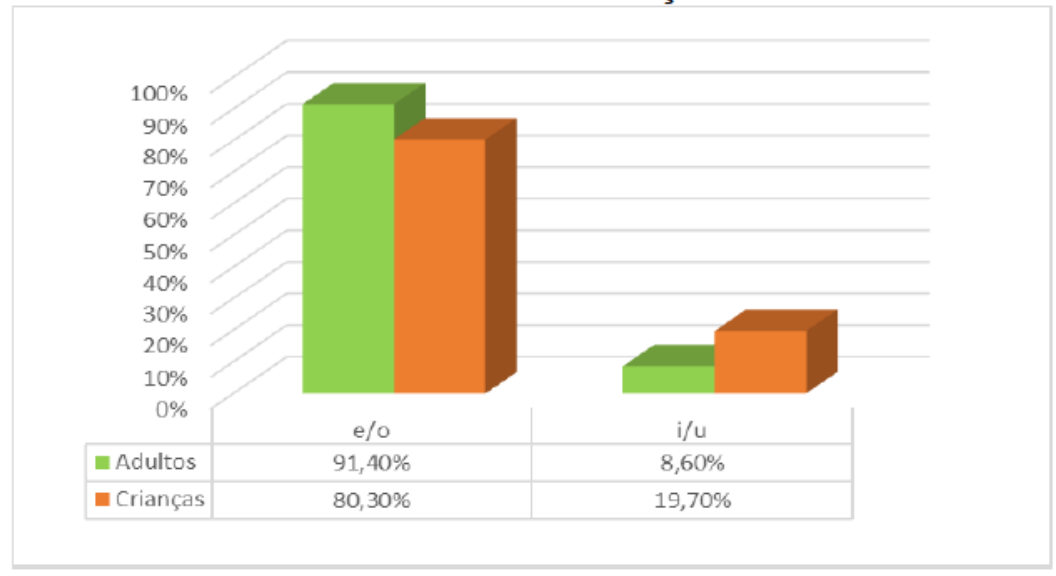

Fonte: Autoral

Os resultados estatísticos obtidos mostram claramente a relação de similaridade entre as produções dos adultos, com percentuais aproximados para as médias altas: $91,4 \%$ na fala dos adultos e $80,3 \%$ na fala das crianças. Quanto aos cuidadores das crianças da FE2 - VAP, observa-se, com base no Gráfico 10, que os resultados confirmam os constatados para os cuidadores da FE1, com percentuais de produção das vogais praticamente iguais nas duas FEs.

Gráfico 6: Percentual de ocorrências das vogais postônicas finais na FE2 Amostra Cuidadores VAP

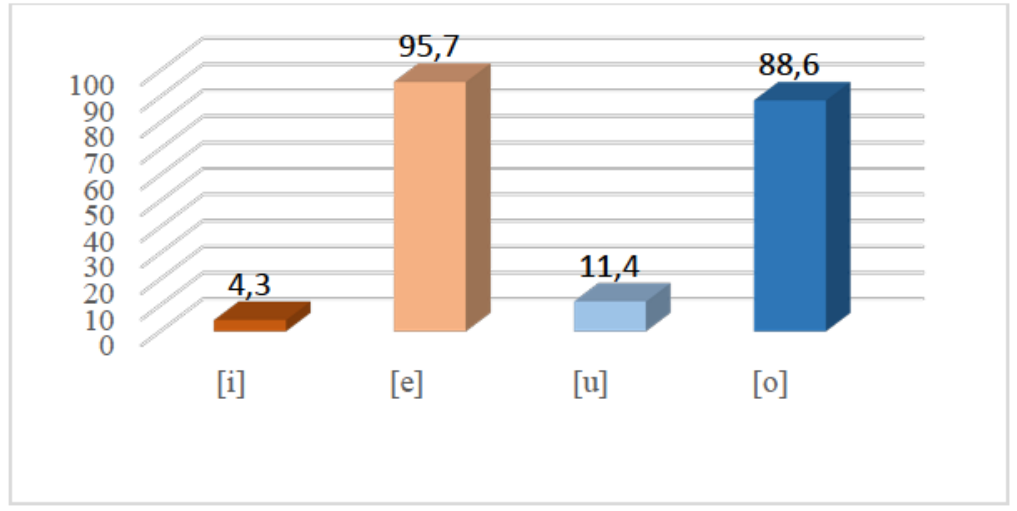

Fonte: Autoral 
Os falantes adultos da FE2 apresentam mais ocorrências das vogais $[e$, o] em suas produções do que das vogais [i, u]. No Gráfico 11 a seguir estão expostos os resultados percentuais.

Gráfico 7: Percentual de ocorrências das vogais postônicas finais - Cuidadores FE2-VAP

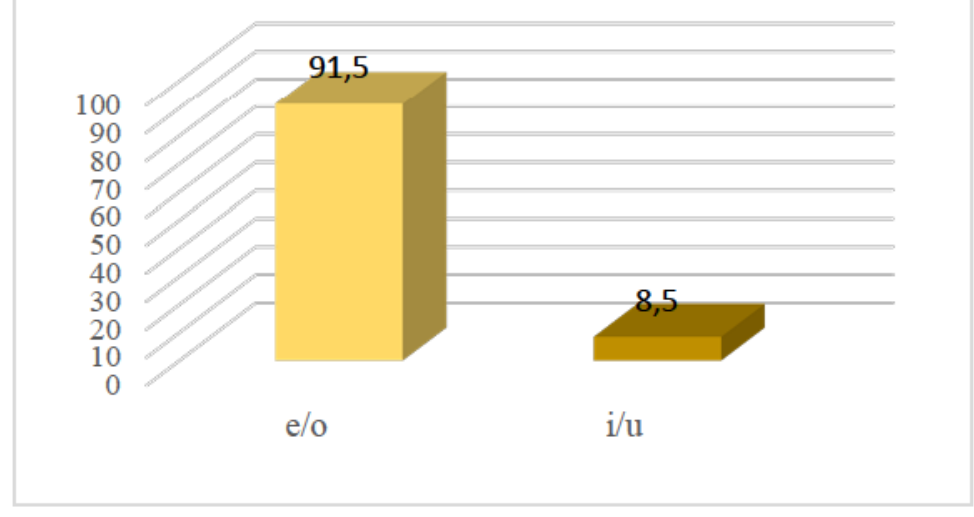

Fonte: Autoral

A similaridade entre os índices de produção das vogais médias altas em posição postônica final na fala dos cuidadores e na das crianças é também constatada para a FE2, conforme mostra o Gráfico 12.

Gráfico 8: Percentuais de ocorrências das vogais médias altas e altas na FE2 - VAP, cuidadores e crianças

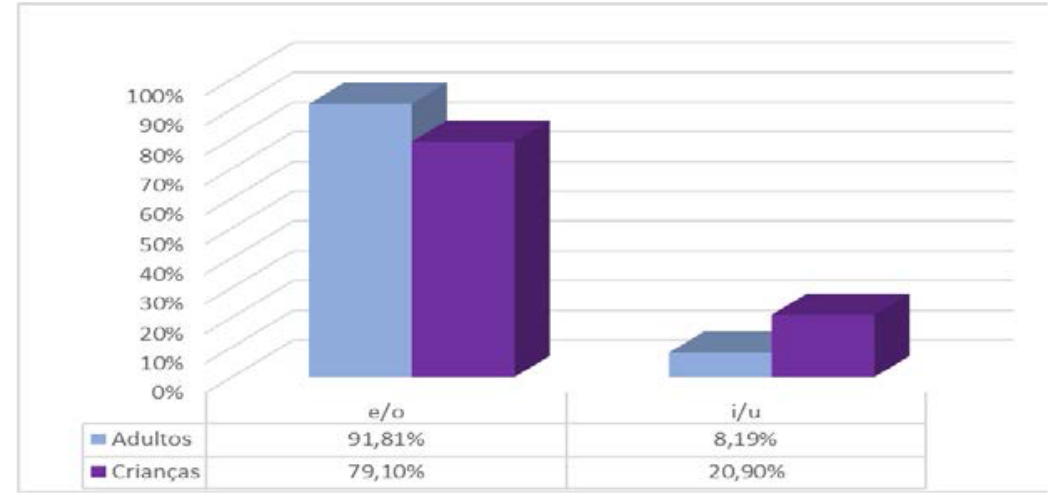

Fonte: Autoral

Assim como os adultos, que apresentaram $91,8 \%$ de realização de vogais médias altas, as crianças também apresentaram alto índice, com 79,1\%.

A investigação do comportamento das vogais átonas finais na fala dos adultos cuidadores dessas crianças mostrou que há semelhança entre os valores obtidos para as crianças e seus cuidadores, principalmente quando se considera a vogal coronal [e]. Observa-se que, tanto para FE1 quanto para FE2, os resultados para as 
vogais médias altas [e, o] ficaram próximos para as crianças e adultos de VAP: para a FE1, as crianças apresentaram $80,3 \%$ e os adultos, $91,4 \%$; para a FE2, as crianças apresentaram $79,1 \%$ e os adultos, $91,8 \%$. Os índices ficam ainda mais similares se forem consideradas as produções da vogal coronal pelas crianças da FE2, pois a vogal média alta atinge $91,5 \%$, bem próximos aos $95,7 \%$ dos adultos. Para a FE1, em que as crianças apresentavam idades entre 1:3 e 1:8, o índice geral da vogal média coronal foi de $84,1 \%$, estando, portanto, um pouco mais distante dos $98,8 \%$ apresentados pelos cuidadores da mesma FE. Esses resultados parecem confirmar o papel da natureza do input no processo de aquisição das postônicas finais, uma vez que, desde as idades mais precoces, são expressivas as similaridades entre as produções de crianças e cuidadores de VAP. Também parecem sinalizar para a emergência da variação, pois com o avançar da aquisição, a partir da FE2, os percentuais de produção de adultos e crianças tornam-se ainda mais similares.

No que se refere aos dados de PEL/POA, tanto as informantes crianças quanto seus cuidadores apresentam apenas as vogais altas na posição átona final, confirmando, portanto, a presença de duas pautas átonas finais. Esses resultados sugerem ainda que o input exerce influência na aquisição da linguagem, no caso deste estudo, na aquisição do sistema átono.

\section{Algumas Considerações}

Esses resultados confirmam a hipótese inicial de que nas comunidades em estudo os comportamentos das vogais médias átonas finais são bastante distintos. Confirma-se, portanto, a importância da variável Localização Geográfica para aplicação ou não do alçamento. Desse modo concluímos que essa variável é a responsável pela presença de duas pautas postônicas finais no Rio Grande do Sul: uma constituída de três vogais [a, i, u] em PEL/POA e outra constituída de cinco vogais postônicas $[a, e, i, o, u]$ em VAP. Esses resultados confirmam também os obtidos para outras localidades do Rio Grande do Sul por Vieira (2002, 2010), Mileski (2013) e Souza (2015). 


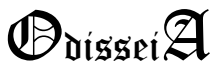

ISSN: 1983 2435

\section{REFERÊNCIAS}

CHOMSKY, N. Aspects of the theory of sintax. Cambridge, MA: MIT Press, 1965.

Reflections on Language. New York: Pantheon, 1975.

Lectures on government and binding: The Pisa lectures. Dordrecht, The Netherlands: Foris Publications, 1981.

FOULKES, P.; DOCHERTY, G.; WATT, D. Tracking the emergence of sociophonetic variation. Proceedings of the 14th International Congress of Phonetic Sciences. Berkeley, CA: University of California, 1999, p.1625-1628.

FOULKES, P.; DOCHERTY, G.; WATT, D. The emergence of structured variation. University of Pennsylvania working papers in linguistics, v. 73, p. 67-84, 2001.

FOULKES, P.; DOCHERTY, G. The social life of phonetics and phonology. Journal of phonetics, v. 34, n.4, p. 409-438, 2006.

JOHNSON, D. E. Getting off the GoldVarb Standard: Introducing Rbrul for mixedeffects variable rule analysis. Language and linguistics compass, v. 2, p. 359-383, 2009.

LABOV, W. Sociolinguistic patterns. Oxford: Blackwell, 1972.

MUNSON, B., EDWARDS, J., BECKMANN, M. Phonological knowledge in typical and atypical speech-sound development. Topics in language disorders, 25, n. 3, p. 190-206, 2005.

PIERREHUMBERT, J. Exemplar dynamics: Word frequency, lenition, and contrast In: BYBEE J.; HOPPER, P. (eds.) Frequency effects and the emergence of lexical structure. Amsterdam: John Benjamins, 2001, p. 137-157.

PIERREHUMBERT, J. Phonetic diversity, statistical learning, and acquisition of phonology. Language and speech. v. 46, n. 2 e 3, p. 115-154, 2003.

MILESKI, I. A elevação das vogais médias átonas finais no português falado por descendentes de imigrantes poloneses em Vista Alegre do Prata - RS. 2013. $152 \mathrm{f}$. Dissertação (Mestrado em Letras) - Pontifícia Universidade Católica do Rio Grande do Sul, Porto Alegre, 2013.

RANGEL, G. A. Aquisição do sistema vocálico do português brasileiro. 2002. 170 f. Tese (Doutorado em Letras) - Pontifícia Universidade Católica do Rio Grande do Sul, Porto Alegre, 2002.

SILVA, S. M. Elevação das vogais médias átonas finais e não finais no português falado em Rincão Vermelho - RS. 2009. 172 f. Dissertação (Mestrado em Letras) Pontifícia Universidade Católica do Rio Grande do Sul, Porto Alegre, 2009. 
SOUZA, S. S. O alçamento das vogais médias átonas finais: uma interface entre aquisição da linguagem e variação linguística. 2015. 265 f. Tese (Doutorado em Letras) - Pontifícia Universidade Católica do Rio Grande do Sul, Porto Alegre, 2015.

TOMASELLO, M. Joint attention as social cognition. In: MOORE, C.; DUNHAM, P. (eds.). Joint attention: its origins and role in development. Hillsdale, $\mathrm{NJ}$ : Erlbaum, 1995, p. 103-130.

Perceiving intentions and learning words in the second year of life. In: BOWERMAN, M.; LEVINSON, S. (eds.). Language acquisition and conceptual development. Cambridge: Cambridge University Press, 2000, p. 132-158.

. Constructing a Language. A usage based theory of language acquisition. Cambridge, MA: Harvard University Press, 2003.

VIEIRA, M. J. B. Neutralização das vogais médias postônicas. 1994. Dissertação (Mestrado em Letras) - Pontifícia Universidade Católica do Rio Grande do Sul, Porto Alegre, 1994.

As vogais médias postônicas: uma análise variacionista. In: BISOL, L.; BRESCANCINI, C. (Org.). Fonologia e variação: recortes do português brasileiro. Porto Alegre: EDIPUCRS, 2002, p. 127-159.

. As vogais médias átonas no sul do Brasil. In: MARÇALO M. J. et al. (Eds.). Língua portuguesa: ultrapassar fronteiras, juntar culturas. Évora: Universidade de Évora, 2010. Disponível em: <http://www.simelp2009.uevora.pt/pdf/slg5/01.pdf>. Acesso em: 01 out. 2012. 